This item was submitted to Loughborough's Research Repository by the author.

Items in Figshare are protected by copyright, with all rights reserved, unless otherwise indicated.

\title{
Rhythms, sociabilities and transience of sexual harassment in transport: mobilities perspectives of the London underground
}

\section{PLEASE CITE THE PUBLISHED VERSION}

https://doi.org/10.1080/0966369X.2020.1734540

\section{PUBLISHER}

Taylor \& Francis (Routledge)

\section{VERSION}

AM (Accepted Manuscript)

\section{PUBLISHER STATEMENT}

This is an Accepted Manuscript of an article published by Taylor \& Francis in Gender, Place and Culture on 4 March 2020, available online: http://www.tandfonline.com/10.1080/0966369X.2020.1734540.

\section{LICENCE}

CC BY-NC-ND 4.0

\section{REPOSITORY RECORD}

Lewis, Sian, Paula Saukko, and Karen Lumsden. 2020. "Rhythms, Sociabilities and Transience of Sexual Harassment in Transport: Mobilities Perspectives of the London Underground”. Loughborough University. https://hdl.handle.net/2134/11889930.v1. 
Lewis, S., Saukko, P. \& Lumsden, K. (version accepted for publication). Rhythms, sociabilities and transience of sexual harassment in transport: Mobilities perspectives of the London underground, Gender, Place and Culture.

Rhythms, sociabilities and transience of sexual harassment in transport:

Mobilities perspectives of the London underground

\begin{abstract}
This article presents an in-depth analysis of women's experiences of sexual harassment in public transport based on 29 qualitative interviews with victims on the London Underground. The article draws on mobility studies to develop an innovative theoretical framework and identifies three key features of experiences of sexual harassment in this space. First, the rhythms of the city (i.e. rush hours and night time) and the Underground facilitated and concealed different forms of sexual harassment. Second, women frequently did not respond to sexual harassment due to respecting the urban civil inattention prevailing on the tube, accentuated by unwillingness to disrupt their fellow passengers' and their own urban trajectories. Third, the transitory nature of the Underground created a situation in which women barely fully registered harassment before it had passed, anticipated it to be over quickly and meant that the perpetrators could disappear into the network. The article suggests that these characteristics of sexual harassment in public transport account for its endemic and underreported nature and offers analytical insights for research on sexual harassment in different context and on different crimes in transport environments.
\end{abstract}

Keywords: gender; mobilities; public transport; rhythm; sexual harassment 


\section{Introduction}

Feminist scholars have examined sexual harassment in public transport from a crime science perspective (Gekoski et al. 2015; Loukaitou-Sideris et al. 2009; Natarajan 2016) and there is also qualitative research on women's experiences of harassment in public transport in the Global South (Bhattacharayya 2015; Butcher 2018; Dunckel Graglia, 2016; Kusters 2019). Sexual harassment has also been discussed in relation to broader issues of gendered mobilities in cities, such as Mumbai and Delhi (Butcher 2018; Kusters 2019). However, it has not been investigated how specific features of mobilities in public transport shape sexual harassment in the context of the Global North.

This article develops and adopts an innovative conceptual framework to discern the characteristics of women's experiences of sexual harassment by drawing on notions of urban rhythms (Lefebvre 1991), codes of comportment or sociabilities in public transport (Goffman 1963; Simmel 1903) and the transient nature of transport environments (Bissell 2010; Urry 2007). Drawing on these concepts the article brings together mobility studies and gender studies to offer the first in-depth qualitative analysis of women's experiences of sexual harassment on public transport in the Global North, specifically the London Underground ('the tube') in the United Kingdom.

The mobilities approach and interviews with female victims draw out three key features of sexual harassment in this space. First, the rhythms of the city facilitate and conceal sexual harassment, which both blends in and is out of place in specific space-time intersections, such as the crowded carriages in the commuter rush hour. Second, women frequently do not respond to sexual harassment due to respecting the urban civil inattention (a deference to strangers in public space) prevailing on the tube, accentuated by unwillingness to disrupt their fellow passengers' and their own urban journeys. Third, the transitory and 
fleeting nature of the Underground creates a situation where women barely fully register harassment before it has passed, anticipate it to be over quickly and means that the perpetrator can disappear into the network. We contend that these characteristics of sexual harassment in public transport account in part for its endemic and underreported nature. Further, the analytical framework also hopes to offer insights for research on sexual harassment in transport and public spaces in other contexts as well as on different crimes in transport environments.

\section{Sexual harassment across contexts}

Feminist work has theorized sexual harassment as part of everyday life across both private and public spheres and has noted that sexual harassment is shaped by the context in which it occurs (Bhattacharyya 2015).

Sexual harassment was first conceptualized in studies on organizational workplaces (MacKinnon 1979). Much of the early scholarship sought to name sexually harassing behaviour in order to curtail it through official organizational and legal channels (MacKinnon 1979). Sexual harassment is conceptualized (in general and specifically in the workplace) as an exertion and abuse of power (Lee et al. 1996). In the workplace sexual harassment is generally perpetrated by men who are known to the victim and related to intimacy, economic dependency and a conflation of relationships of power (Schneider 1991).

Sexual harassment in public spaces, such as the street, is different as it is typically perpetrated by men who are strangers to the victim (Bowman, 1993). Sexual harassment in public spaces is becoming recognised as one of the most common forms of violence against women (Kelly 1987; Vera-Gray 2016). Such harassment includes unwelcome physical contact or advances, stalking, lewd gestures and voyeurism, as well as verbal behaviours (Sur 
2014). Gardner $(1995,121)$ describes sexual harassment in public space to include 'scrutiny, exhibitionism, enmeshing service encounter, public aid exchanges or greetings with innuendo and romantic overtones and determined following'. Pain $(1991,421)$ has defined such behaviour as 'unwanted intrusive acts perpetrated by men against women, including staring, touching and comments or actions of a sexual nature'. In India, street harassment is often called 'eve teasing' (Dhillon \& Bakaya 2014), and a type of cat calling, sometimes understood by men as a form of gallantry and colloquially called pirópo is pervasive in Latin America (Bailey 2017). Similarly to sexual harassment in the workplace, feminist scholars have conceptualised street harassment as acts of gendered dominance and violence underpinned by inequality (Tuerkheimer 1997).

Street harassment contributes to a general sense of women's vulnerability and inequality in urban spaces, as discussed by generations of feminist geographers (Bondi \& Rose 2003) by restricting space (Pain 1997; Mehta 1999) and mobility, or contributing to what Cynthia Bowman (1993) terms 'the informal ghettoization of women'. Significant theoretical work has also discussed how women perceive such acts as intrusions (Bowman 1993; Vera-Gray 2016), which violate their privacy and general codes of civil inattention (Goffman 1963).

Bowman (1993) highlights that women often react to public harassment in a nonconfrontational way due to fear of escalation, fear of being perceived as impolite, societal pressure and 'lines' not being crossed by the harasser. Dhillon and Bakaya (2014) state that women's responses to sexual harassment often include a combination of self-protective strategies and emotional reactions of fear and anger.

Sexual harassment in public transport has many similarities to street harassment (i.e. it is commonly perpetrated by strangers). However, this article contends that the spatial, social 
and temporal nature of urban public transport account for the unique ways in which sexual harassment is experienced and perpetrated in this space.

\section{Sexual Harassment on Public Transport}

Feminist geographers have addressed gender inequalities in transport, drawing attention to the fact that women often have different travel needs to men (Little 1994) and raised awareness of the fear of sexual violence that many women experience when using public transport and how this limits their mobility and freedom (Law 1999). Gender has been recognized by transport authorities to impact on travel needs and has gradually been considered in the designing of policy and practice, such as the creation of female-only carriages in Mexico City, Mumbai and Tokyo (Hamilton et al. 2005; Kusters 2019; Loukaitou-Sideris et al. 2009; Horii \& Burgess, 2012; Dunckel-Graglia 2016).

Recent studies in different national contexts have explored the frequency and nature of sexual harassment in transit (Horii \& Burgess 2012), underreporting (Solymosi et al. 2017; Smith 2008), and the impact of sexual harassment on women's behaviour and future travel (Loukaitou-Sideris \& Fink 2008; Koskela \& Pain 2000). Gardner et al. (2017) note that most sexual harassment in transit is nonconfrontational, although it can be confrontational in the form of groping, touching or leaning (Hsu 2011). Adiv (2017) has offered a personal account of groping on airplanes and how this gets downplayed by authorities. Dunckel-Graglia (2016) explored public discourses on women only carriages in Mexico City's public transit noting a pervasive notion that women brought harassment upon themselves or even 'liked' it and Kusters (2019) has discussed female-only carriages in Mumbai in terms of both women's safety and maintaining appropriate gender behaviour. 
With regards to trains and buses, behaviour that is frequently reported includes lewd comments, leering, sexual invitations, stalking, masturbation, frotteurism (rubbing the pelvic area or erect penis against a non-consenting person for sexual pleasure (Lim 2000) and unwanted sexual touching (Gekoski et al. 2015; Shoukry et al. 2008). Much of this can be considered in terms of what Goffman $(1963,143)$ calls 'exploitation of contact'. The space is significant here. The overcrowded nature of transport at peak rush hour time permits bodily contact and the perpetration of sexual harassment in a particular embodied way (Neupane $\&$ Chesney-Lind 2014; Chui \& Wong 2008; Gardner et al. 2017). Smith and Clarke (2000) consider other aspects of the environment, including poor surveillance and supervision, and a lack of patrolling on public transport. Gekoski et al. (2015) also recognise that the context of public transport as an overcrowded, isolating and hard to control environment, may facilitate particular types of sexual harassment. Neupane \& Chesney-Lind (2014) reported that in Kathmandu, Nepal women were reluctant to respond to sexual harassment due to fear of public condemnation. They also observed that the busyness of the space can permit men to offend anonymously, with little risk of exposure. Furthermore, they noted how the motion of transport covered up intentional bodily contact, deliberate rubbing against a victim appearing accidental bumping into them.

These analyses highlight important features of women's experiences of sexual harassment in public transport, such as offenders taking advantage of crowded spaces and jerking motions to inappropriately touch women. Thus there are clear differences between what is happening in transport in comparison to on the streets and in organizational settings. Sexual harassment in transport is often committed as a solitary, anonymous act, and there is less evidence of sexual harassment being perpetrated as a performance of heterosexual masculinity for male peers, which has been observed in the streets or workplace (Quinn 2002; Bailey 2017). Acknowledging how the nature of sexual harassment varies in relation to the 
context, helps to demonstrate how the space, and normative social interactions within that space, impact on how incidents are experienced and perpetrated. In order to explore experiences of sexual harassment in the particular context of the London Underground, this article draws on the field of mobility studies and particularly the concepts of 'rhythm' and 'civil inattention'.

\section{Sexual Harassment, Rhythm, Sociabilities and Transience}

Space plays an active role in the construction and reproduction of social interactions (de Certeau 1984; Lefebvre 1991). Referring to criminal activity in a transit environment, Ceccato and Uittenbogaard $(2014,133)$ state how 'at an underground station crime is a product of two dimensions- the environment and the social interactions that take place in these environments'. The significance of time has also been recognised, along with the environment, as impacting human movement and activity (Rose 1993). Thus, spatialtemporalities (or time-space geography) structure women's experiences of crime in transit, recognizing that environmental factors increase levels of fear and perceived risk (poor lighting, lack of visibility, etc.) (Gilchrist et al. 1998) and influence when actual incidents of crime in transit environments occur (Ceccato \& Uittenbogaard 2014; Loukaitou-Sideris et al. 2009). When discussing the impact of space and time on interactions in public transport, it is useful to take a mobilities perspective.

The mobilities paradigm or 'mobility turn' (Urry 2000) in the social sciences sought to address the complex yet neglected role that mobilities, or the movement of people and things, play in the (re)configuration of social interactions and the social world.. Kusters $(2017,2019)$ uses a mobilities approach to explore 'the mutual shaping of intersectionality and mobility' considering spatial practices and the intersection of gender and deafness in 
Mumbai trains. Butcher (2018) and Kusters (2019) have used a mobilities perspective to explore how women negotiate spaces, infrastructures, social norms, interactions and intersectionality in India, also addressing sexual harassment. We take a slightly different approach to mobilities and explore sexual harassment in public transport in terms of urban rhythms taking a conceptual lead from Lefebvre's (2004) work.

Lefebvre suggests that rhythm analysis 'deepens the study of everyday life' (2004, 73) and considers how: 'Everywhere where there is interaction between a place, a time and an expenditure of energy, there is rhythm' $(2004,15)$. Most commonly used within mobility studies (Edensor 2010, 2011; Bissell 2007) and human geography (Cresswell \& Merriman 2011; Stratford 2015), the concept of rhythm has been operationalised to analyse aspects of everyday life in the city, including commuting (Edensor 2010) and the night-time economy (Schwanen et al. 2012). This study draws on the rhythm analysis perspective and acknowledges Lefebvre's (2004) insistence that time and space must be considered as interrelated in order to understand the patterned and repetitive ebbs and flows of everyday life, such as cities that pulsate in accordance with rush hours and quiet periods.

Rhythms are present in a multiplicity of forms; they can be biological, psychological, social and mechanical; corporeal, natural, institutional and collective (Schwanen et al. 2012). Lefebvre (2004) discusses how tensions exists between rhythms. He considers that whilst often acting in repetitive harmony, rhythms may also collide with one another. In his work on the politics of mobility, Cresswell (2010) recognizes rhythm and friction as important components of mobility. He describes friction as a social and cultural phenomenon that can be lived and felt when our mobility is prevented or slowed down, both involuntarily and out of choice (Cresswell 2013), such as border control or stopping to take in a scenic view. The concept of friction is relevant for sexual harassment on the Underground, as women's mobilities are often disrupted, rather than stopped altogether, leading to 'blockages' (Marston 
et al. 2005) in mobility. There are multiple rhythms interacting on the Underground, often in tension with one other: rhythms that are historically produced and socially and structurally reproduced. As an extension of Victorian railways, the Underground constituted part of a public mobilization and 'new connectedness' (Urry 2007, 91) where masses of people were able to move freely through extended time and space (Lewis, 2018) creating new sites of sociability.

These mobilities manifest daily in the form of circadian rhythms of the city that permeate the Underground, rhythms of the Underground itself and the often linear rhythms of the passengers, including female victims, journeying from one place to another. In this article it is argued that sexual harassment in transport occurs at the interstices of these rhythms, which facilitate and conceal it.

Further, rhythms create particular sociabilities that occur within the fast paced, transitory environment where people move from one place to another. As an urban public space, the Underground is permeated by what Goffman (1971) calls 'civil inattention', a deference owed to strangers in a crowded public space. Whilst necessary for selfpreservation, civil inattention can create a hostile environment and foster feelings of indifference and a lack of individual or social responsibility as was explored by Simmel (1903) with his conceptualization of 'metropolitan individuality'. Sociabilities in public transport are further regulated by the exigencies of transport, where passengers are particularly irritated if their journeys are interrupted (Edensor, 2010).

Finally, a characteristic feature of transport experiences is transience, as Urry (2007) notes travel is marked by fleeting, ephemeral encounters. Bissell (2007) further discusses how waiting in transit environment is often active, saturated with different affects and characterized by anticipation for the event-to-come (next stop, arrival). These observations 
are relevant for understanding experiences of sexual harassment in transport, which have often already passed before the woman fully registers and reacts to the situation and where the anticipation of the journey or harassment being soon over structures women's response. The empirical section of this article is framed in terms of rhythms of the city, sociabilities on the Underground and the transience of transport. This framework allows connecting instances of sexual harassment to general time-space structures of the city and the transport network, illustrating how harassment is, in part, a problem of space-time.

\section{Methods}

This article draws on data from 29 qualitative interviews with women who had experienced sexual harassment on the London Underground Network. Participants were recruited via a 'call for participants' disseminated on the social media sites Twitter and Facebook via the first author's personal accounts. On Twitter, the call was retweeted 111 times: 10 participants were recruited this way. On Facebook, the call was shared 75 times: 6 participants were recruited this way. Significantly, the call was posted on a highly followed and active feminist Facebook group page (now no longer in existence): 12 participants were recruited via this page. The call was also published on the NGO Hollaback! (whose work focuses on sexual harassment in public) Facebook page; 2 participants were recruited in this way. In total 29 participants were recruited and interviewed. None of the participants were personally known to the researchers.

Interviews were conducted between October 2016 and October 2017. Participants were between the age of 21 and 45 (the average being 30). Twenty-four (24) of the women were white, three were Asian and two defined themselves as mixed race; 23 were British 
whilst seven identified as non-British nationals; three identified as gay, two as bisexual and 24 as heterosexual.

The interviews were open ended and covered three broad topics. Firstly, women were asked about their experiences of London and use of the Underground in general. Then, we moved on to discuss the specific incident(s) of sexual harassment, how it made them feel and how they reacted to it at the time. Finally, the interview focused on reflecting on how/if they felt the experience had impacted them over time. The call for participants did not define what behaviour was inclusive of sexual harassment. Therefore, each participant self-defined their experiences of sexual harassment. Some participants spoke of incidents that happened the previous week, month or year. Others recalled incidents from their teenage years. The majority of interviews took place face-to-face in London, and three were conducted via Skype. All interviews were recorded and fully transcribed. Analysis was on-going throughout the data collection process, thereby taking a 'spiral' or iterative-inductive approach (O'Reilly 2009; 2012), allowing for the emergence and discovery of themes. The data was analysed using a thematic analysis (Nowell et al. 2017). This involved a familiarisation with the data and the drawing out of predominant themes; samples of transcripts were read and discussed by members of the team.

This study also included observations on the London Underground, conducted by the first author. This totalled approximately 180 hours of observations over a 9 month period between October 2016 and June 2017. The aim of the observations was to understand the nature and sociabilities of the space in different areas, on different lines, and at different times of day. Whilst observations have not been directly used in this article, they offered insights the space of the Underground and helped to develop the conceptual framework of rhythms (Lefebvre 2004) and friction (Cresswell 2010). 
The study was approved by the University's ethics committee. The anonymity of participants was ensured throughout by the use of pseudonyms within this article. Taking a qualitative, feminist approach helped the researcher to foster interactions where women were free to talk about or avoid subjects where they felt appropriate (Campbell et al. 2009). Many women spoke not just of their experiences of sexual harassment on the tube, but also referred to other types of gendered victimisation that they had experienced in their lives. Interviews were sometimes emotional for participants, and therefore the researcher attempted to foster an engaged, empathetic and emotionally reflexive interaction whilst making sure participants were not guided to speak about issues they were not comfortable sharing. In the remainder of the article, we discuss in detail the three themes which emerged from the interviews in terms of how experiences of sexual harassment were shaped by (i) rhythms of the city, (ii) sociabilities and mobilities on the tube, and (iii) the temporary, transient nature of the environment.

\section{Findings}

\section{Rhythms, Facilitation and Concealment of Sexual Harassment}

The rhythms of the city permeated the Underground and facilitated and concealed sexual harassment in various ways, at different times of day. This was particularly pertinent in morning and evening rush hours when passengers were pressed up against one another on platforms and in the rail carriage. This density of bodies permitted particular types of sexual harassment to be perpetrated, most commonly frotteuring (rubbing against someone with an erection) or groping. Ruth described how she was wedged between other commuters in a busy morning rush hour carriage: 
I felt someone's hand touch me really closely on my pubic bone... So somebody had gone in with the tips of their fingers and palm up and gone underneath ... I felt the fingers move from side to side like a pendulum on my pubic bone.

Multiple scales are at play here. Whilst harassment is implicated by the wider macro rhythms of the city and the Underground network, rhythms and friction became more micro, intimate, individual and corporeal in the space of the tube where bodies are pressed against each other (Lefebvre 2004). Ruth described how despite the normality of "people touching you, being in your personal space' on the tube, this felt different 'there was no way this was accidental...it felt deliberate'. Thus, the rhythms of the tube facilitated and concealed the invasion of her body and space. Sheila described a similar experience implicated by the busyness of the network (a consequence of the rhythms of the city):

He had a hard on and he was rubbing against me ... But because it was so crowded in there I couldn't immediately ... in my head I was thinking it was a bag or an umbrella or something, because nobody would do that would they... he was stood behind me at this stage rubbing on my leg and bum ... I think I was frightened you know, I didn't want to make a fuss on the tube ... I was tempted to turn around but what if it is just a bag or umbrella, then I'll look really stupid.

During morning rush hour, the rhythms of harassment were only subtly out of line with the 'correct or regular movements of the daily commute' (Cresswell 2010, 25), permitting the digression from normal behavior in that space to go unnoticed by bystanders and even initially by the victim. This related to Lefebvre's (2004) claim that rhythms both reveal and 
conceal. Despite the invasiveness of these incidents, the way in which the perpetrator moved with the choreographies of the crowd and synchronized with the rhythmic motion of the carriage, instilled enough uncertainty that the women questioned what was happening and therefore did not react overtly. Without visibly transgressing from the dominant and acceptable way of behaving, the normative physical friction that occurred between passengers was exploited to perpetrate and conceal a particular type of harassment.

The modus operandi of sexual harassment differed depending on the time of day. Other exploitations of the rhythms of the city and the tube included perpetrators enacting overtly sexual behaviour when the space/carriage was isolated at off-peak times. This came most commonly in the form of masturbating or exposure. Grace was 14 years old when she was on an empty off-peak tube on her way home on the outskirts of the city. She described how a man got on the next carriage and stared at her through the interconnecting doors. She felt uneasy but wasn't sure why. His behaviour was almost barely outside the realm of 'normal' yet by protracting a sustained gaze, civil inattention (Goffman 1963), was breached enough to make her uncomfortable. At the next stop, he got on her carriage, and sitting away from her, started to masturbate under a sheet of newspaper. To an outsider, his predatory actions would be almost imperceptible; he exploited the nature of the space, at a particular time (for example, this behaviour would have been difficult to perpetrate unnoticed in a busy rush hour carriage) and, by not directly touching her, he did not interject the public transit norms of non-verbal or nonrepresentational modes of communication (Bissell 2010, 271).

Romanticized sexual harassment (Gardner 1995) appeared more commonly at night. Spontaneous, ambiguous interactions, often fuelled by alcohol, are a part of the night-time economy (Brands et al. 2013). With many Londoners using the tube as way to get home late at night, these interactions permeated even the conspicuously anti-social nature of the Underground. Whilst in many circumstances such fleeting interactions can be a source of 
connectedness (Hubbard 2012; Urry 2007), in these situations they acted as the foundation for anxiety or fear. Jules was on her way home from a late work event on a Friday night when a man got on to the train and started talking to her. She said 'I was happy to chat, I thought he had recognised me as a fellow gay person and just wanted to have a drunk chat'. However, he quickly propositioned her for sex and became aggressive when she said no:

He got grumpy and kept grabbing at me, so I stood up and walked and sat on a different chair, and he followed me. At this point I was sitting down and he was standing over me, leaning in...I'm not sure if he was trying to kiss or touch my face, but he kept doing that and coming towards my face. I put my hands firmly in the middle of his chest, pushing him away, saying no, go away.

Rose described how she was on a late night Saturday tube that was full of drunk people. She considered how the nature of the network changed at this time of night and became a more social space. She stated, 'There's a different vibe... after a night out people are less embarrassed and less polite, there's license to do whatever they want to do ... maybe more pushy in their conversation'. She described how a man she had got chatting to during her journey 'suddenly out of the blue leant down and kissed me right on the lips'. She pushed him away and he got off the tube at the next stop. She said: 'He wasn't being malicious, he was just overstepping the mark, an idiot, he was drunk... he just thought he had the right to do that'.

At this time of night, Simmel's (1903) ‘blasé outlook’ or Goffman's (1963) notion of 'civil inattention' (which are observable in rush hours) lose a part of their functionality and passengers become more willing to interact with those around them. As Urry $(2007,109)$ 
states, trains can indeed be 'places of unexpected interchange'. Fleeting or prolonged interactions are observable when travelling on the tube in the evening, often impacted by alcohol consumption, and the ambiance of the carriage.

Thus, the nature of sexual harassment on the Underground network was shaped by the macro rhythms of the city and its spatio-temporal variations. Different incidences of sexual harassment, on one hand, blended in with the more intimate rhythms on the tube, such as the jostling of bodies in the crowded rush hour carriages, or the informal, sometimes alcoholfueled chatter in the night trains, facilitating and concealing it. On the other hand, experiences of sexualized groping seemed out of place in the morning commuter train, making it difficult for women to initially recognize what was happening to them and to formulate a response to it. Thus, the reinforcement and disruption between the rhythms of the city, the tube and sexual harassment caused distress and confusion for women as they attempted to negotiate the ambiguity and uncertainty of the situation in a confined, transitory environment.

\section{'Civil Inattention' on the Tube}

On the Underground there are acceptable modes of behaviour or sociabilities. The prevailing norm of civil inattention, observed to permeate public spaces (Goffman 1971), is reinforced by the norm of not disrupting the journeys or trajectories of fellow passengers (Edensor 2010). These norms structured women's experiences of sexual harassment on the tube.

Eliza was a victim of frotteuring. She described how she 'just wanted to push him away, shout at him.' However, she was worried that reacting overtly would disrupt the social order of the carriage, saying: 'I didn't want to deal with the embarrassment or humiliation of people looking at me, judging me and probably not even helping'. This feeling overrode her bodily desire to respond to the incidence, showing the pervasiveness of normative rhythms 
and the sociabilities they construct. A response in this context would risk losing face (Goffman 1955), which can result in embarrassment and tension. Consequently, she made the decision not to 'cause a scene'. This was mirrored by other participants who, after experiencing sexual harassment on a busy carriage, felt unable to react overtly, particularly as this would have entailed disrupting the main aim of everyone in the carriage, to get from one place to another as quickly as possible. Emmy stated how she felt unable to speak out:

It's really hard to break that silence...there's no eye contact...there's no talking, everyone's in their own world, trying to get through it because it's the part of the day that's a means to an end, trying to get to work. Nobody is present, they're just getting through it as quickly as possible.

The transitory and mobile nature of the tube carriage makes it what Auge $(2006,31)$ describes as 'placeless'- 'places which are marked by an abundance of mobility'. As highlighted above by Emmy, the sole purpose of being on public transport is in order to get somewhere else (Urry 2007). Consequently, travellers generally want to minimise the time they spend in such spaces (Bissell 2010). This links to what Goffman (1963) terms 'allocation involvement' where in travel environments the main focus of the individual is to get to their destination, while other involvements are secondary and worth avoiding if possible. Indeed, this had an impact on how some women reacted to their experiences of sexual harassment in transit, as they did not want to disrupt their own trajectories. When a man rubbed up against Charlie during evening rush hour, she stated: 
I wanted to get off the tube, but also I didn't because I wasn't where I wanted to be...I was entitled to be there and using it to get home, getting off would have slowed me down.

Carla who was on her way to meet a friend for dinner, describes similarly how, when a man started masturbating across the carriage from her, she made the decision to stay where she was: 'Walking away wasn't an option, and I was already late, so I just kind of looked away and stayed on until my stop'.

These accounts underline the impact of normative sociabilities, specific to public transport, on women's agency, as they negotiate experiences of sexual harassment. When women notice they are being sexually harassed, the fear of breaking the codes of comportment and creating friction in the social situation and for everyone's journey had significant implications. Women describe an unwillingness to overtly react for both fear or embarrassment, and the apprehension that their fellow passengers will react with ambivalence or condescension. Furthermore, when dealing with their experiences of sexual harassment whilst in transit, women actively refused to cause further disruption to their own journeys or mobilities.

It has been noted that women do not react to sexual harassment in transit for fear of escalating the situation and for embarrassing themselves (Neupane \& Chesney-Lind 2013, Horii \& Burgess 2012). The women on the London Underground were not typically fearful of escalating the situation during the commuter rush hour, which probably tells something about the specificity of a Northern metropolis at a particular time of day. However, they did not want to break the code of civil public conduct, in particular fearing that fellow passengers would be annoyed and unresponsive due to their main aim in the environment being to get 
quickly and without disruption to their destination. Furthermore, the women also did not want to disrupt their own trajectories, which links with what Gardner (1995) observed in relation to the women who felt they were managing power by not reacting during or after experiencing sexual harassment. Despite their discomfort and agitation, these women refused to slow down and disrupt their own trajectory and mobile rhythms, resisting the friction that was posed by this intrusion.

\section{The 'Transitory' Nature of the Underground}

Finally, as Urry $(2007,109)$ states, railway stations and trains are '...places of unexpected social interchange as people's lives from distant parts are contingently brought together, often only for 'brief encounters: before the characters move away'. This ephemeral nature of public transport has a significant effect on sexual harassment. Some of the women who participated in the research described how their experiences of sexual harassment on the Underground were initially shrouded by uncertainty as to what was happening. This held particularly true for experiences of harassment during rush hour. This uncertainty led to them barely having time to process or react to the incident in a way that they felt was appropriate. Kath was groped between her legs on a busy evening tube:

I'm like, I'm reasonably sure I'm being assaulted... You sort of second-guess yourself don't you, which I think is a significant thing about the tube ... because you've got that window. Is that? Maybe they're not doing it deliberately ... Second-guessing, maybe he doesn't like the draft near the door ... all this ... going on in my head ... it's that fatal period of: is it? By the time you've worked it out, you've missed your window to make a fuss. 
Kath highlights the significance of temporality and transience here, stating that there is an appropriate 'window' in which to make a fuss, which, due to her taking time to realize what was happening, she missed. Demi also stated that 'by the time I really realized, like properly, what was going on, that he was like actually rubbing against me, it was too late to say anything because it was my stop'. Cris described a man assaulting her during rush hour:

I was so engrossed in my book I wasn't aware of the people coming and going around me ... then slowly I felt this growing pressure on my pelvis. I didn't even really notice at first I don't think until it was really hard ... This old man's fist was pressing into me ... I was in shock, like is this really happening, how did I not notice? I think then we pulled into a stop and he either got off or moved away...But this is the thing with the tube and being used to having people in your personal space, even after I was still like did that happen? Did he mean to?

These experiences question the notion that women often do not react overtly simply out of fear (Pain 1991). This is not to argue that women do not experience fear when being sexual harassed. Rather, it contributes to feminist work that has insisted that women should not be portrayed as inherently fearful and passive, highlighting other factors that implicate women's experiences and reactions (Nehta \& Bondi 1999). As Koskela (1997) claims with regards to women's reactions to street harassment, feelings of fear and boldness are often experienced simultaneously. Alongside this, these examples demonstrate that within this rhythmic and transient space, a situation is created where uncertainty is an equally significant feeling that must be negotiated. 
Another significant aspect of the ephemeral nature of a transport environment is that women are occupied with the notion that the situation is temporary. This impacted women's decisions to engage with their harasser, on the premise that the journey, and therefore the situation, would soon be over. Emmy described her decision to stay where she was whilst a man rubbed against her from behind, in the hope that the interaction would not be prolonged: 'I thought grit your teeth and wait for the next stop, maybe he'll get off...but he didn't'. Moving between stops, the tube carriage was temporarily isolated from the 'outside world', increasing the notion of entrapment (Urry 2007) and Emmy's sense of being unable to directly remove herself from the situation without disrupting the carriage. Yet the fluctuating nature of the transit environment permitted her punctuated moments of hope that the perpetrator would disembark. This demonstrates how the conflict between the rhythms of being physically stationery, whilst simultaneously moving through space impact upon women's reactions to sexual harassment in a transitory environment. Similarly, when a man was pushing up against her, Layla described how at every stop she thought about trying to leave the situation by using the flux and influx of people to move away: 'I kept thinking at the hustle and bustle of each stop I could move or get off', but she didn't, explaining 'I just kept thinking, well only three, two, one more stops to go'. Reflecting on an experience of a man masturbating on an empty carriage when she was 14, Grace remembers thinking: 'only one stop to go, how long can that take? Apparently a really, really long time'.

Whilst time is said to be compressed by high-speed rail travel (Urry 2007), these examples illustrate the interaction and friction between various rhythms (particularly the mechanical speed of the tube and Grace's psychological rhythms), and what Edensor (2010, 190) considers 'the subjective experience of the rhythmic and temporal' which 'may vary so that time can drag'. In this instance, the harasser's abnormal behaviour acted as a friction; it slowed down of her perception of time, as she experienced the distance between stops in a 
different way, yet she endured the situation in anticipation of it being over soon, as the train was moving towards the destination. The perpetrators also exploited the transitory, temporary nature of the space in order to 'slip away' after they had committed their offence. As Ruth stated:

Then the doors opened and everyone got off...the guy got off...everyone carries on with their journey...the tube, it's such an ephemeral thing, you're not there for long, you just get through it like oh it'll be over in a minute...And then you think, the moment's passed, there's nothing I can do about it.

Eliza similarly discussed how after groping her on a rush hour tube the man 'slunk away down the carriage... he got off and then disappeared into the mass of people'. Here, a lack of friction, and the constant movement of both trains and individuals occurring with network acted to enable (at least the perception of) the harasser to disappear into the network.

Thus, the transient nature of public transport shaped the women's experiences of and reactions to sexual harassment. The fleeting nature of the encounter between the victim and the perpetrator resulted in the women not having sufficient time to mentally process what was happening to them and to formulate a response before the situation was over. Further, the anticipation that the situation would soon resolve, as the train would reach the next stop as the moment-to-come (Bissell 2007), influenced women not to react to the situation. These features of the transport space and the fleeting momentary time, imbued with anticipation of the journey and situation being over make it understandable why women do not react to or challenge sexual harassment in these environments, where the encounter soon dissolves and the perpetrator disappears. 


\section{Discussion and conclusion}

Feminist scholarship on sexual harassment has drawn attention to its pervasiveness in the workplace and public spaces, whilst noting that incidents occur and are experienced differently depending on context. This article contributes a new perspective to this research by focusing on public transport and using a mobilities perspective to discern the specificities of experiences of sexual harassment in this environment. What is important here is that the experiences of sexual harassment are shaped by the fact that the environment is mobile. The Underground is an environment where space and time intersect in a particular way, and exploring these particularities pinpoints three key features that shape the way in which sexual harassment occurs in this space and how it is experienced by women.

Firstly, the rhythms of the city and the Underground create a unique polyrhythmic ensemble (Lefebvre 2004) at the intersection between the macro rhythms of the city and the micro rhythms of the Underground and the jostling bodies of the journeying passengers, resulting in the facilitation and concealment of sexual harassment. This time-space context is different to that of the streets, even though both are public spaces. The rhythms of the Underground facilitate particular types of harassment to be perpetrated. On the streets 'cat calling' and verbal forms of harassment are common (Vera-Gray 2016; Gardner 1995). On the tube, particularly during rush hour, the volume of people in a contained space allows for more physical and embodied acts of sexual violence, such as frotteuring and groping. Equally, the rhythmic jostling of bodies in a restricted space often conceals what is happening, as women struggle to immediately discern whether inappropriate touches are accidental or not, which impacts and delays their response. It has been observed that the crowded nature of transport permits sexual harassment to go undetected (Gardner, 2017). This article further elaborates these observations by linking sexual harassment to the rhythms of the city and the Underground and demonstrating how this delays women's responses as the 
experience of unexpected pushing and shoving simultaneously seems normal and out of place in the space and time. Further, the rhythms of the city also facilitated different types of sexual harassment at different times, so rush hours and night time were inductive of different experiences that both fitted in and disrupted expectations in that space and time.

Secondly, the sociabilities shaping women's responses to sexual harassment, including civil inattention are specific to public transport. In the workplace, sexual harassment is perpetrated by and amongst people who are known by the victim and often in a direct power relation to her. On the streets and in public transport, harassment is predominantly committed amongst strangers. However, streets and transport are also different; various forms of cat calling on the street often articulate a display of masculinity, which can also happen in organizational contexts. In transport sexual harassment is often a solitary, anonymous act and rarely involves an audience but is rather characterized by concealment.

Researchers have reported that women often do not respond to sexual harassment in public spaces, including transport, fearing embarrassment, escalation and public condemnation, fear of violence and repercussions to the victim being particularly prominent in some parts of the global South (Neupane \& Chesney-Lind, 2013). We did not often observe women fearing the violence would escalate, although this was sometimes a concern at night and in nearly empty carriages. However, what was also significant in the tube was that women did not want to make a scene and disrupt the codes of comportment or sociabilities of urban, public transport, in particular civil inattention, fearing for embarrassment and lack of support from bystanders. Further, this desire to minimize disruption was exacerbated by the fast paced and transitory nature of the tube, as women felt particularly self-conscious that other passengers wanted to continue their journeys without disruption, fearing fellow travellers would be annoyed by any blockages to their journeys, as 
has been observed by Edensor (2010). Interestingly, many women also did not react to sexual harassment, making sometimes a conscious choice not to allow the incidence to disrupt or slow down their journeys. These observations highlight that besides respecting the code of public behaviour, the women's reactions in transport were also shaped by the orientation of the experience towards journeying, where harassment would put an end to the intended action and outcome of reaching a destination for both bystanders and the victim.

Finally, the transitory and fleeting nature of the tube was important as to how women experienced sexual harassment. The fleeting nature of the experience of public transport made it difficult for women to be certain they were being sexually harassed before it was almost too late to react — the window had passed, as powerfully commented by one participant. In the workplace, it is often difficult for women to envisage the end of sexual harassment due to its repeated perpetration. This then means adopting coping mechanisms or taking significant action to curb the harassing behavior (Krasas \& Henson 1997). On the Underground, women often anticipated that the situation would soon come to an end. This anticipated resolution was often an incitement not to actively engage with the occurrence. The transient nature of transport also facilitated the apparent immediate disappearance of the perpetrator into the network, as also noted by Neupane and Chesney-Lind (2014), which could be a relief but also made this type of harassment attractive for the perpetrator as it allowed for a relatively easy escape.

In conclusion, a mobilities approach to sexual harassment on the Underground helps to discern the specific features of sexual harassment on public transport. The approach permits an exploration of how the urban and transport rhythms coalesce and intertwine to shape and facilitate the perpetration of, victims' experiences of, and responses to, sexual harassment. A mobilities perspective brings to the forefront how these experiences are shaped by the fact that they are happening in a mobile environment. Our research also contends that 
the specific characteristics of sexual harassment in public transport account for its endemic nature, make it difficult to tackle, and where efforts to encourage women to report incidences do not bode well with the nature and flow of this environment.

The analytical perspective, drawing on mobility studies and focusing on rhythms, sociabilities and transience, developed in this article also hopes to offer insights for further research on sexual harassment in public and transport context in different social, cultural and geographical environments. Further, the mobilities perspective delineated here may also help to discern and understand features of other types of crime, such as hate crime and robbery, in transport.

\section{Acknowledgements}

The researchers would like to thank all the women who took part in this research and shared their experiences with us. This project was partly funded by the Police Innovation Fund and Loughborough University's research facilitation funds. 


\section{References}

Augé, Marc. 2006. Non-places: An introduction to supermodernity. Brooklyn, NY: Verso.

Bailey, Benjamin. 2017. Greetings and compliments or street harassment/ Competing evaluations of street remarks in a recorded collection. Discourse \& Society 8(4): 353- 373.

Benson, Donna, Gregg Thomson. 1982. Sexual Harassment on a University Campus: The Confluence of Authority Relations, Sexual Interest and Gender Stratification, Social Problems 29(3): 236-251

Bhattacharyya, Rituparna. 2015. Understanding the spatialities of sexual assault against women in India. Gender, Place \& Culture 22(9): 1340-1356.

Bissell, David. 2007. Animating suspension: Waiting for mobilities, Mobilities, 2, 2, 277-98. Bissell, David. 2010. Passenger mobilities: Affective atmospheres and the sociality of public transport, Environment and Planning D: Society and Space 28(2): 270-289.

Bondi, Liz \& Rose, Damaris (2003). Constructing gender, constructing the urban: A review of Anglo-American feminist urban geography, Gender, Place and Culture, 10:3, 229-245

Bowman, Cynthia. 1993. Street harassment and the informal Ghettoization of Women. Harvard Law Review 106(3): 517- 580. 
Brands, Jelle, Tim Schwanen, Irina van Aalst. 2013. Fear of Crime and affective ambiguities in the night-time economy. Urban Studies 53(3): 439-455.

Brant, Claire, Yun Lee Too. (eds). 1994. Rethinking sexual harassment, London: Pluto Press. Butcher, Melissa. (2018). Defying Delhi’s enclosures: strategies for managing a difficult city, Gender, Place and Culture, 25: 5, 727-742.

Campbell, Rebecca, Adrienne Adams, Sharon Wasco, Courtney Ahrens, Tracy Sefl. 2009. Training Interviews for Research on Sexual Violence: A qualitative study of rape survivors' recommendations for interview practice. Violence Against Women 15(5): 595-617.

Ceccato, Vania, Adriaan Cornelius Uittenbogaard. 2014. Space-time dynamics of crime in transport nodes. Annals of the Association of American Geographers 104(1): 131-150.

Cresswell, Tim. 2010. Towards a Politics of Mobility. Environment and Planning D: Society and Space 28(1): 17-31.

Cresswell, Tim. 2013. Friction. In The Routledge Handbook of Mobilities, edited by Peter Adey, David Bissell, Kevin Hannam, Peter Merriman, Mimi Sheller. London and New York: Routledge. 
Dhillon, Megha, Suparna Bakaya. 2014. Street harassment: A qualitative study of the experiences of young women in Delhi. SAGE Open: 1-11.

Dunckel Graglia, Amy. 2016. Finding mobility: women negotiating fear and violence in Mexico City's public transit system. Gender, Place \& Culture 23 (5): 624-640.

Edensor, Tim. 2010. Commuter: Mobility Rhythm and Commuting. In The Geographies of Mobilities: Practices, Spaces, Subjects, edited by Tim Cresswell, Peter Merriman. London: Routledge.

Fairchild, Kimberley, Laurie Rudman. 2008. Everyday stranger harassment and women's objectification. Social Justice Research 21(3): 338-357.

Gardner, Carol Brooks. 1995. Passing By: Gender and Public Harassment. Berkeley: University of California Press.

Gardner, Natalie, Jianqiang Cui, Eddo Coiacetto. 2017. Harassment on public transport and its impact on women's travel behaviour. Australian Planner 54(1): 8-15.

Gekoski, Anna, Jacqueline Gray, Miranda Hovarth, Sarah Edwards, Aliye Emirali, Joanna Adler. 2015. 'What Works' in reducing sexual harassment and sexual offences on public 
transport nationally and internationally: A rapid evidence assessment. London: British Transport Police and Department for Transport.

Gilchrist, Elizabeth, Jon Bannister, Jason Ditton, Stephen Farrall. 1998. Women and the 'fear of crime': Challenging the accepted stereotype. British Journal of Criminology 38(2): 283298.

Goffman, Erving. 1971. Relations in Public: Microstudies of the public order. London: Allen Lane.

Goffman, Erving. 1963. Behaviour in Public Places: Notes on the Social Organizations of Gatherings. London: Collier-Macmillan.

Goffman, Erving. 1955. On Face-Work: An analysis of ritual elements in social interaction. Psychiatry: Interpersonal and Biological Processes 18(3): 213-231.

Hamilton, Kerry, Linda Jenkins, Frances Hodgson, Jeff Turner. 2005. Promoting Gender Equality in Transport, Equal Opportunities Commission 34.

Horii, Mitsutoshi, Adam Burgess. 2012. Constructing Sexual risk: 'Chikan’, collapsing male authority and the emergence of women-only trains in Japan. Risk \& Society 14(1): 41-55. 
Hornsey, Richard. 2012. Listening to the tube map: rhythm and the historiography of urban map use. Environment and Planning D: Society and Space 30(4): 675-693.

Hsu, Hsin-Ping. 2011. How does fear of sexual harassment on transit affect women's use of transit? Transportation Research Board Conference Proceedings 2(46): 85-94.

Hubbard, Phil. 2012. Cities and Sexualities. New York: Routledge. Kelly, Liz. 1987. The continuum of sexual violence. In Women, Violence and Social Control, edited by Mary Manard, Jalna Hamer. London: Palgrave Macmillan UK.

Kimmel, Michael. 2008. Guyland: The Perilous World Where Boys Become Men: Understanding the Critical Years between 16 and 26. New York: Harper Collins.

Kissling, Elizabeth Arveda. 1991. Street harassment: The language of sexual terrorism. Discourse \& Society 2(4): $451-460$.

Koskela, Hille. 1997. 'Bold Walk and Breakings': Women's spatial confidence versus fear of violence. Gender, Place and Culture, 4 (3): 301-320.

Krasas, Jackie Rogers, Kevin Henson. 1997. “Hey, Why Don’t You Wear a Shorter Skirt ?” : Structural vulnerability and the organization of sexual harassment in temporary clerical employment. Gender and Society 11(2): 215- 237. 
Kusters, Annelies. (2019). Boarding Mumbai trains: the mutual shaping of intersectionality and mobility, Mobilities. Online first.

Lefebvre, Henri. 1991. The Production of Space. Oxford: Basil Blackwell. Lefebvre, Henri. 2004. Rhythmanalysis, Space, Time and Everyday Life. London: Bloomsbury.

Lim, Leslie. 2002. Sexual assaults in Singapore: A comparative study of rapists and molesters. Medicine, Science and the Law 42(4) 344-350.

Little, Jo. 1994. Gender, Planning and the Policy Process. Oxford: Pergamon. Lonsway, Kinberley, Rececca Paynich, Jennifer Hall. 2013. Sexual Harassment in Law Enforcement, Incidence, Impact and Perception. Police Quarterly 16(2): 177210.

Loukaitou-Sideris, Anastasia, Amanda Bornstein, Camille Fink, Linda Samuels, Shanin Germai. 2009. How to Ease Women's Fear of Transportation Environments: Case Studies and Best Practices. Mineta Transportation Institute.

Loukaitou-Sideris, Anastasia, Camille Fink. 2009. Addressing women's fear of victimization in transportation settings: A survey of U.S transit agencies. Urban Affairs Review 44(4): 554 $-587$. 
Loukaitou-Sideris, Anastasia. 2014. Fear and safety in transit environments from the women's perspective. Security Journal 27(2): 242-256.

MacKinnon, Catherine. 1979. Sexual Harassment of working women: A case of sex discrimination. New Haven; London: Yale University Press.

Marston, Sallie, J.P. Jones, Keith Woodward. 2005. Human geography without scale, Transactions of the Institute of British Geographers 30(4): 416-432.

Mehta, Anna. 1999. Embodied discourse: On gender and fear of violence. Gender, Place \& Culture 6(1): 67-84.

Natarajan, Mangai. 2016. Rapid assessment of 'eve teasing' (sexual harassment) of young women during the commute to college in India. Crime Science 5(1): 6.

Neupane, Gita, Meda Chesney-Lind. 2013. Violence against women on public transport in Nepal: sexual harassment and the spatial expression of male privilege. International Journal of Comparative and Applied Criminal Justice 38(1): 22-38.

Nowell, Lorelli, Jim Norris, Deborah White, Nancy Moules. 2017. Thematic Analysis:

Striving to meet the trustworthiness criteria. International Journal of Qualitative Methods 16: $1-3$. 
O’Reilly, Karen. 2009. Sage Key Concepts: Key Concepts in Ethnography. London: Sage.

Pain, Rachel. 1991. Space, sexual violence and social control: integrating geographical and feminist analyses of women's fear of crime. Progress in Human Geography 15(4): 415-431.

Quinn, Beth. 2002. Sexual harassment and masculinity: The power and meaning of "girl watching”. Gender \& Society 16(3): 386- 402.

Rose, Gillian. 1993. Feminism and geography: the limits of geographical knowledge. Cambridge: Polity.

Schneider, Beth. 1991. Put up and shut up: Workplace sexual assaults. Gender \& Society 5(4): 533-548.

Schwanen, Tim, Irina van Aalst, JelleBrands, Tjerk Timan. 2012. Rhythms of the night; Spatiotemporal inequalities in the night-time economy. Environment and Planning A: Economy and Space 44(9): 2064-2085.

Simmel, Georg. 1903. The Metropolis and Mental Life. In The Blackwell City Reader. 2002. Edited by Gary Bridge, Sophie Watson. Oxford: Blackwell. 
Solymosi, Reka, Kerry Cella, Andrew Newton. 2017. Did they report it to stop it? A realist evaluation of the effect of an advertising campaign on victims' willingness to report unwanted sexual behaviour. Security Journal 31(2): 570-590

Smith, Martha J. 2008. Addressing the security needs of women passengers on public transport. Security Journal 21(1-2): 117-133. Smith, Martha J, Ronald V. Clarke. 2000. Crime and Public Transport. Crime and Justice 27: 169-233.

Stringer, Scott. 2007. Hidden in Plain Sight: Sexual Harassment and Assault in the New York City Subway System. Office of the Manhattan Borough President.

Tuerkheimer, Deborah. 1997. Street harassment as sexual subordination: The phenomenology of gender-specific harm. 12 Wis. Women's L.J 167. College of Law Faculty Publications. Paper 177.

Urry, John. 2007. Mobilities. Cambridge: Polity.

Vera-Gray, Fiona. 2016. Men's stranger intrusions: rethinking street harassment. Women's studies international forum 58: 9-17. 